\title{
Review Article: Regulatory T Cells in Colorectal Cancer
}

\author{
Morteza Jafarinia $^{1}$ (D), Noushin Lotfi ${ }^{1}$ (D, Mazdak Ganjalikhani-hakmi ${ }^{1}$ (D), Abbas Rezaei ${ }^{*}$ (iD)
}

1. Department of Immunology, School of Medicine, Isfahan University of Medical Sciences, Isfahan, Iran.

Chtaton Jafarinia M, Lotfi N, Ganjalikhani-hakmi M, Rezaei A. Regulatory T Cells in Colorectal Cancer. Immunoregulation. 2018; 1(1):5-10. http://dx.doi.org/10.32598/Immunoregulation.1.1.5

http://dx.doi.org/10.32598/Immunoregulation.1.1.5

Article info:

Received: 07 September 2016

Accepted: 18 May 182017

Available Online: 01 April 2018

Keywords:

Colorectal cancer, $\mathrm{T}$ regulatory cells, Immune suppression

\begin{abstract}
A B S T RA C T
One of the essential protection mechanisms of immune system is Treg cells which play an important role in maintenance of immune homeostasis. However, they may also inhibit immune functions against tumor cells. It has been reported that Treg cells are increased in patients suffering from different types of cancer. Increased number of Treg cells has been shown in tumor lymph nodes, peripheral blood, and tumor sites of patient with Colorectal Cancer (CRC). However, it is clear that Treg cells are increased in CRC patients, but the prognostic impact of Treg cells in CRC patients is a matter of debate. It seems that the function of these cells depend on the stage of CRC development. The aim of the present review article is to make an attempt to provide vision on the role of Treg in CRC. Finally, the potential approaches for the treatment of CRC are discussed.
\end{abstract}

\section{Introduction}

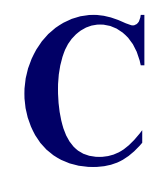

olorectal Cancer (CRC) develops in the colon or rectum and is the third most common cancer and the third leading cause of death due to cancer in the US [1]. This cancer is usually asymptomatic, so screening is essential in detecting it. The main risk factors for this cancer include alcohol, red meat, obesity, smoking, lack of physical exercise, and genetic predisposition [2].

Treg cells are specific population of $\mathrm{T}$ cells with suppression/regulatory properties and play a major role in maintenance of self-tolerance. These cells comprise $5-10 \%$ of the circulating $\mathrm{CD} 4+$ population. The initial characteristic phenotype of Tregs is CD4+CD25+ [3]. However, CD25 expression cannot be used in human studies. Previous studies have suggested that peripheral blood isolated from an outbred human population contains up to $30 \% \mathrm{CD} 4+$ $\mathrm{CD} 25+\mathrm{T}$ cells; only $1-2 \%$ of cells with the highest CD25 expression have been shown to be functionally suppressive and can be considered as Tregs [4]. Besides CD4 and $\mathrm{CD} 25$, transcription factor FoxP3 is also required for isolation of Treg cells. In fact, Foxp3 is specifically required for Treg cell development [5]. Recent studies have shown that human Tregs are functionally and phenotypically diverse.

Treg cells can be classified in two main subtypes: naturally occurring Treg cells, which are CD4+CD25hi $\mathrm{CD} 127$ lowFoxP3 + Helios + and induced regulatory $\mathrm{T}$

\footnotetext{
* Corresponding Author:

Abbas Rezaei, PhD.

Address: Department of Immunology, School of Medicine, Isfahan University of Medical Sciences, Isfahan, Iran

Phone: +98 (31) 37929060

E-mail: rezaei@mui.ac.ir
} 
cells (iTreg) which are generated in the periphery. These iTreg can exert their suppressive effects through production of IL-10 and TGF- $\beta[4,6]$. Moreover, there are Foxp3 negative suppressor $\mathrm{T}$ cells, including $\mathrm{Tr} 1, \mathrm{Th} 3$ cells, CD8+CD28+/-, and Qa1-restricted T cells [7, 8]. Treg cells also could be divided in to three categories based on CD45RA expression and intensity of FoxP3 expression: 1) CD45RA+FoxP3low resting Treg cells, 2) CD45RAFoxP3hi activated Treg cells, and 3) cytokine-secreting CD45RA-FoxP3low non-Treg cells [9]. In addition to CD25 and FoxP3, there are other markers that have been shown to express on Treg cells, including CD127 [10], CTLA-4 [11], GITR [12] and HLA-DR [13]. There is also another classification of Treg cells based on the expression of HLA-DR and CD45RA: Naïve Tregs (CD45RA+, HLA-DR-), memory Tregs (CD45RA-, HLA-DR-), and memory/activated Tregs (CD45RA-, HLA-DR+) [14].

Treg cells play a critical role in inflammation resolution and restoration of immune homeostasis. They can functionally suppress immune responses by influencing the activity of another cell type [15], including CD4+ and CD8+ T cells, Natural Killer and NKT cells, B cells, and AntigenPresenting Cells (APCs) [16]. In spite of this activity, sometimes Treg cells play negative roles in immune system and could protect virus or carcinoma from immune clearance and promote diseases development [17].

\section{Treg Cells in Cancer}

Regulatory $\mathrm{T}$ cells play an important role in cancer, although partially controversial role. In many human cancers, the prevalence of Treg and their suppressor actions are increased as compared to those reported for healthy participants [18-20]. Despite the general concept that Treg aggregation in cancer is related with poor prognosis [21-23], several reports have demonstrated that Treg numbers and activity are associated with improved prognosis [24-28]. While the role of Treg in tumor growth, progression to metastasis, and the disease outcome are still controversial, there is considerable experimental and clinical evidence that Treg plays a crucial role in suppression of antitumor immune responses and so contributes to tumor escape from the host immune system $[28,29]$. Different studies showed an increase of Treg cells in circulation, draining lymph nodes, and the tumor site of patients with malignancies [30, 31].

The potential of Treg application either for protection from tissue destruction by activated $\mathrm{T}$ cells or for invasion against antitumor effector immune cells has led to a more extensive attention of mechanisms that support Treg recruitment to tissue sites. It is accepted, for example, that Treg express Toll-Like Receptors (TLRs), and that TLR li- gands can control functions of Treg, presumably including their migration [32]. Employment of Treg to tumor sites is regulated by chemokines formed in the Tumor Microenvironment (TME) such as, CCL22, a ligand for CCR4 [33]. Activated Treg express several chemokine receptors (i.e. CCR4, CCR5, CCR6, CCR7, and CCR10) that can mediate Treg trafficking to tumor micro environment [34].

In the presence of tumor-derived chemokines, Treg gather in the tumor site, and, before taking place, progress to prevent antitumor responses of immune cells penetrating the TME. Hence, Treg which accumulate in situ and in the peripheral circulation of cancer patients can be noticed as one of multiple attempts by the tumor to develop its own escape from the host immune system by dampening antitumor immune effector cells. On the other hand, it looks likely that in tumors characterized by vast inflammatory infiltrates, such as colon or breast cancers, Treg are vital for controling chronic inflammation, preventing tissue damage, and reducing tumor development associated with inflammation $[35,36]$.

Several studies have suggested that many cancers can induce proliferation of Treg cells from naïve T cells. It is also shown that the presence and number of Treg in the tumor are associated with improved prognosis in patients with colon or breast carcinomas [28, 35, 37, 38]. Recently, the origin and phenotypic features of Treg infiltrating human tumors have been a matter of debate $[39,40]$ and although rapid progress have been made in our understanding of how Treg work, many conditions of their interactions with the tumor and other immune or non-immune cells remain ambiguous [41, 42].

\section{Regulatory T Cells in CRC and Controver- sial Function of Treg Cells in CRC}

CRC is one of the most common cancer and cause of the death in the world [1]. Treg cells could have an important role in $\mathrm{CRC}$, and have potential roles in therapeutic strategies [43]. Increased number of Treg cells has been shown in tumor lymph nodes, peripheral blood, and tumor site in patients with CRC $[15,44,45]$. It is also shown that Treg cells could infiltrate lymph nodes in patients with CRC. These cells have critical roles in the colon and are necessary for homeostasis and maintaining intestinal immune tolerance in colon. The abundance of Treg cells in the colon is due to commensal microbiota and colonic DCs which are tolorogenic in this part of body. Reduction of Treg cells have been shown in the germ free mice or vancomycin-treated mice [46]. 
Recently, Treg cells have received special attention because of their inhibitory role on effector $\mathrm{T}$ cells and high number of these cells that enable the cancer cells to evade the host immune responses [47]. Previous studies were shown that Treg cells in patients are specific for a set of Tumor Associated Antigens (TAAs), suggesting that Treg suppress other cells in an antigen selective manner [48].

Several studies have shown that anti-tumor T cell immune responses were enhanced in mice after depletion of Treg cells subpopulation by anti-CD25 monoclonal antibodies. Also, high number of tumor infiltrating FoxP3 cells has been associated with poor overall survival of patients with solid tumors [49-51]. So, it is reasonable to consider that high level of Treg cells in CRC patients can inhibit antitumor response and cause immune escape of tumor cells and disease progression [51]. One study showed that after Treg cells depletion, there will be an increase in effector $\mathrm{T}$ cells responses against TAAs in CRC patients [48].

Although Treg cells are increased in CRC patients, the prognostic impact of Treg cells in these patients is a matter of debate. Different studies support the different roles of Treg cells in CRC patients. In one study, it was shown that the density of FoxP3 cells infiltrating CRCs was significantly higher in parallel with enhanced number of $\mathrm{CD} 8+\mathrm{T}$ cells in CRC with level microsatellites instability [52]. Also, several other studies have reported that high density of Treg cells in Sentinel Lymph Node could suppress the antitumor immune response, whereas in CRC patients, Treg cells correlate with increased tumor protection and survival [53].
Different studies suggested that in early stages of CRC, Treg cells may have a protective role by suppressing cancer-associate inflammation, but after conversion of the Treg cells into a pro-inflammatory phenotype, this benefit is lost [54]. On the other hand, in early carcinogenesis, Treg cells are able to limit the inflammation that ultimately leads to cancer [29]. One report showed that high number of intratumoral FoxP3 cells is associated with better survival of CRC patients [45]. In fact, the role of Treg cells in CRC patients depend on the type of immune responses in the tumor microenvironment and the stage of the disease. Treg cells may be beneficial when inflammatory cells that promote tumor progression are dominate; however, Treg cells may promote tumor progression and suppress the anti-tumor immunity when the immune response is dominated by $\mathrm{T}$ cells [45]. Treg cells can also convert into pro-inflammatory Th17 cells under strong inflammatory stimuli and lead to cancer initiation [55].

\section{Potential Approaches for Treatment of CRC}

Targeting Tregs may suggest an important therapeutic plan as an adjunct to the treatment of patients besides surgery and neoadjuvant chemotherapy [45]. In fact, it is determined that immunosuppression by $\mathrm{T}$ - reg cell is one of the vital tumor immune-evasion mechanisms and the main restriction of successful tumor immunotherapy [56]. Treg cells are necessary to tumor-induced peripheral tolerance and are an obstacle to tumor immunotherapy. Some cytotoxic agents systemically deplete Treg cells, and Treg modulation in patients with CRCs might progress antitumor immunity or the response to immunotherapy [50, 57]. It is also reported that depletion of Tregs in the peripheral blood

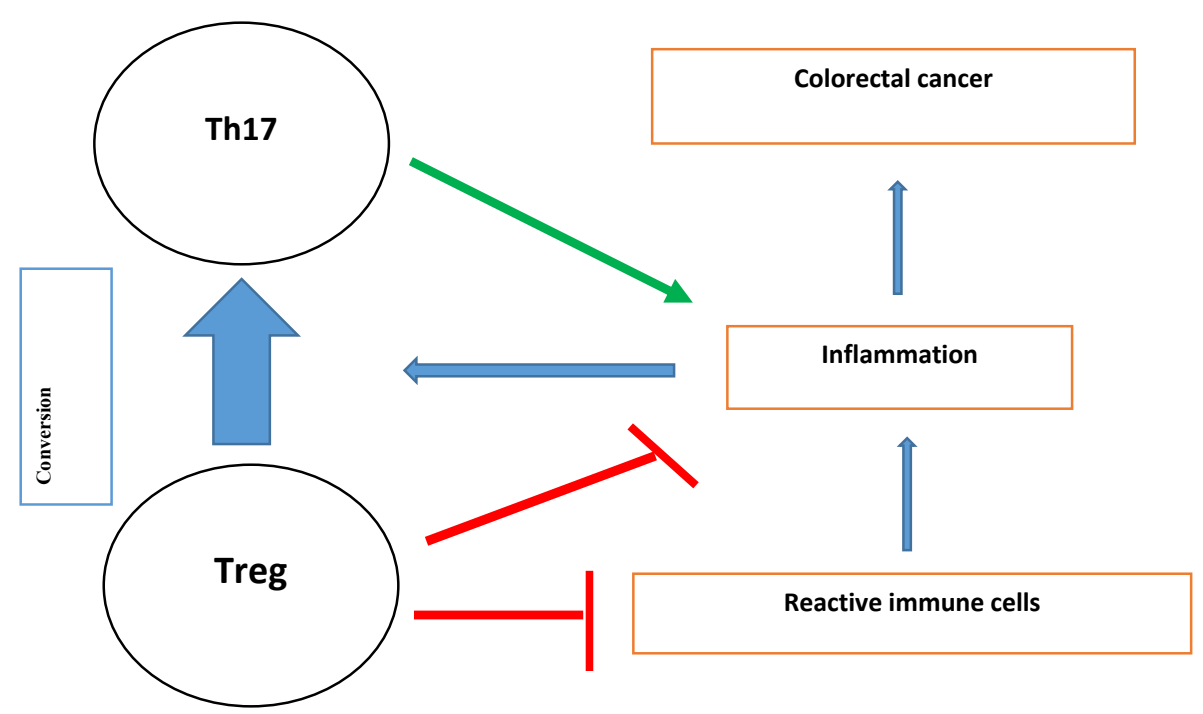

Figure 1. Role of Treg in colorectal cancer

IMMUNoREGULATION

Conversion of Treg cells into Th17 cells can initiate the colorectal cancer. 
of patients with $\mathrm{CRC}$ enhances $\mathrm{CD} 4+\mathrm{T}$ cell responses to Tumor- Associated Antigens (TAAs) [48].

However, the profit or risk of Tregs increase in CRC is currently controversial. Some reports concluded that using Tregs for immunotherapy has a strong preclinical animal database, which support the safety and efficacy of Treg immunotherapy protocols in patients who need induction of clinical tolerance, like allograft tolerance, atopic and autoimmune disease, and acute inflammatory disorders [58]. However, because there are differences between Tregs and Effector T cells in the supply of the known TAAs, alternative choice is testing selected TAAs for tumor vaccinations that motivates suitable effector T-cell responses but reduces Treg activity, which may boost the efficacy of vaccination programs without the need for depletion of Tregs [54].

\section{Concluding Remarks}

$\mathrm{CRC}$ is one of the most common cancers in the world having a significant impact on the health care outcomes. Already it is known that Treg cells increase and enrich in CRC patients. But the action of these cells is still a matter of debate. It seems that the function of these cells depend on the stage of CRC development. In the early stages, Treg cells play a positive role by suppressing the inflammatory cells and inflammation. However, when effector cells dominate in the tumor microenvironment, they play a negative role by suppressing the effector cells. So, learning more about the exact role of these cells in CRC patients can help us to adopt different strategies to manipulate Treg cells and eventually improve the patient survival.

\section{References}

[1] Strum WB. Colorectal adenomas. The New England Journal of Medicine. 2016; 2016(374):1065-75. [DOI:10.1056/NEJMra1513581] [PMID]

[2] Nisar B, Faizi KS, Ali A. Different clinical presentations of patients with Colorectal Cancer.

[3] Wang YM, Ghali J, Zhang GY, Hu M, Wang Y, Sawyer A, et al. Development and function of Foxp3+ regulatory T cells. Nephrology. 2016; 21(2):81-5. [DOI:10.1111/nep.12652] [PMID]

[4] Saito T, Nishikawa H, Wada H, Nagano Y, Sugiyama D, Atarashi K, et al. Two FOXP3 + CD4+ T cell subpopulations distinctly control the prognosis of colorectal cancers. Nature Medicine. 2016; 22(6):679-84. [DOI:10.1038/nm.4086] [PMID]

[5] Rampling R, Peoples S, Mulholland PJ, James A, Al Salihi O, Twelves CJ, et al. A Cancer research UK first time in human phase I trial of IMA950 (novel multi peptide therapeutic vac- cine) in patients with newly diagnosed glioblastoma. Clinical Cancer Research; 2016.

[6] Sebastian M, Lopez Ocasio M, Metidji A, Rieder SA, Shevach EM, Thornton AM. Helios controls a limited subset of regulatory T cell functions. The Journal of Immunology. 2016; 196(1):14455. [DOI:10.4049/jimmunol.1501704] [PMID] [PMCID]

[7] Haque M, Song J, Fino K, Sandhu P, Song X, Lei F, et al. Stem cell-derived tissue-associated regulatory $\mathrm{T}$ cells ameliorate the development of autoimmunity. Scientific reports. 2016; 6. [DOI:10.1038/srep20588]

[8] Haque M, Fino K, Lei F, Xiong X, Song J. Utilizing regulatory $\mathrm{T}$ cells against rheumatoid arthritis. Frontiers in oncology. 2014; 4:209. [DOI:10.3389/fonc.2014.00209] [PMID] [PMCID]

[9] Miyara M, Yoshioka Y, Kitoh A, Shima T, Wing K, Niwa A, et al. Functional delineation and differentiation dynamics of human $\mathrm{CD} 4+\mathrm{T}$ cells expressing the FoxP3 transcription factor. Immunity. 2009; 30(6):899-911. [DOI:10.1016/j.immuni.2009.03.019] [PMID]

[10] Seddiki N, Santner Nanan B, Martinson J, Zaunders J, Sasson S, Landay A, et al. Expression of interleukin (IL)-2 and IL-7 receptors discriminates between human regulatory and activated T cells. The Journal of Experimental Medicine. 2006; 203(7):1693-700. [DOI:10.1084/jem.20060468] [PMID] [PMCID]

[11] Wing K, Onishi Y, Prieto Martin P, Yamaguchi T, Miyara M, Fehervari Z, et al. CTLA-4 control over Foxp3+ regulatory T cell function. Science. 2008; 322(5899):271-5. [DOI:10.1126/ science.1160062] [PMID]

[12] Levings MK, Sangregorio R, Sartirana C, Moschin AL, Battaglia M, Orban PC, et al. Human CD25+ CD4+ T suppressor cell clones produce transforming growth factor $\beta$, but not interleukin 10, and are distinct from type $1 \mathrm{~T}$ regulatory cells. The Journal of experimental medicine. 2002; 196(10):1335-46. [DOI:10.1084/jem.20021139] [PMID] [PMCID]

[13] Baecher Allan C, Wolf E, Hafler DA. MHC class II expression identifies functionally distinct human regulatory $\mathrm{T}$ cells. The Journal of Immunology. 2006; 176(8):4622-31. [DOI:10.4049/jimmunol.176.8.4622] [PMID]

[14] Chevalier MF, Didier C, Petitjean G, Karmochkine M, Girard PM, Barré-Sinoussi F, et al. Phenotype Alterations in Regulatory T-Cell Subsets in Primary HIV Infection and Identification of Tr1-like Cells as the Main Interleukin 10Producing CD4+ T Cells. Journal of Infectious Diseases. 2015; 211(5):769-79. [DOI:10.1093/infdis/jiu549] [PMID]

[15] Zou W. Regulatory T cells, tumour immunity and immunotherapy. Nature Reviews Immunology. 2006; 6(4):295-307. [DOI:10.1038/nri1806] [PMID]

[16] Sakaguchi S, Miyara M, Costantino CM, Hafler DA FOXP3+ regulatory $\mathrm{T}$ cells in the human immune system. Nature Reviews Immunology. 2010; 10(7):490-500. [DOI:10.1038/nri2785] [PMID]

[17] Wang Q, Feng M, Yu T, Liu X, Zhang P. Intratumoral regulatory $\mathrm{T}$ cells are associated with suppression of colorectal carcinoma metastasis after resection through overcoming IL-17 producing T cells. Cellular immunology. 2014; 287(2):100-5. [DOI:10.1016/j.cellimm.2014.01.002] [PMID]

[18] Mougiakakos D, Choudhury A, Lladser A, Kiessling R, Johansson CC. Regulatory $\mathrm{T}$ cells in cancer. Advances in 
cancer research. 2010; 107:57-117. [DOI:10.1016/S0065230X(10)07003-X]

[19] Strauss L, Bergmann C, Gooding W, Johnson JT, Whiteside TL. The frequency and suppressor function of CD4+ CD25highFoxp3+ $\mathrm{T}$ cells in the circulation of patients with squamous cell carcinoma of the head and neck. Clinical Cancer Research. 2007; 13(21):6301-11. [DOI:10.1158/1078-0432. CCR-07-1403] [PMID]

[20] Wolf AM, Wolf D, Steurer M, Gastl G, Gunsilius E, GrubeckLoebenstein B. Increase of regulatory $\mathrm{T}$ cells in the peripheral blood of cancer patients. Clinical Cancer Research. 2003; 9(2):606-12. [PMID]

[21] Curiel TJ, Coukos G, Zou L, Alvarez X, Cheng P, Mottram $\mathrm{P}$, et al. Specific recruitment of regulatory $\mathrm{T}$ cells in ovarian carcinoma fosters immune privilege and predicts reduced survival. Nature Medicine. 2004; 10(9):942-9. [DOI:10.1038/ nm1093] [PMID]

[22] Wolf D, Wolf AM, Rumpold H, Fiegl H, Zeimet AG, Muller-Holzner E, et al. The expression of the regulatory $\mathrm{T}$ cell-specific forkhead box transcription factor FoxP3 is associated with poor prognosis in ovarian cancer. Clinical Cancer Research. 2005; 11(23):8326-31. [DOI:10.1158/1078-0432. CCR-05-1244] [PMID]

[23] Deng L, Zhang H, Luan Y, Zhang J, Xing Q, Dong S, et al. Accumulation of foxp3+ T regulatory cells in draining lymph nodes correlates with disease progression and immune suppression in colorectal cancer patients. Clinical Cancer Research. 2010; 16(16):4105-12. [DOI:10.1158/10780432.CCR-10-1073] [PMID]

[24] Badoual C, Hans S, Rodriguez J, Peyrard S, Klein C, Agueznay NEH, et al. Prognostic value of tumor-infiltrating CD4+ T-cell subpopulations in head and neck cancers. Clinical Cancer Research. 2006; 12(2):465-72. [DOI:10.1158/10780432.CCR-05-1886] [PMID]

[25] Tzankov A, Meier C, Hirschmann P, Went P, Pileri SA, Dirnhofer S. Correlation of high numbers of intratumoral FOXP3 + regulatory T cells with improved survival in germinal center-like diffuse large B-cell lymphoma, follicular lymphoma and classical Hodgkin's lymphoma. Haematologica. 2008; 93(2):193-200. [DOI:10.3324/haematol.11702] [PMID]

[26] Carreras J, Lopez Guillermo A, Fox BC, Colomo L, Martinez A, Roncador G, et al. High numbers of tumor-infiltrating FOXP3-positive regulatory $\mathrm{T}$ cells are associated with improved overall survival in follicular lymphoma. Blood. 2006; 108(9):2957-64. [DOI:10.1182/blood-2006-04-018218] [PMID]

[27] Farinha P, Al-Tourah A, Gill K, Klasa R, Connors JM, Gascoyne RD. The architectural pattern of FOXP3-positive $\mathrm{T}$ cells in follicular lymphoma is an independent predictor of survival and histologic transformation. Blood. 2010; 115(2):289-95. [DOI:10.1182/blood-2009-07-235598] [PMID]

[28] Droeser R, Zlobec I, Kilic E, Güth U, Heberer M, Spagnoli $G$, et al. Differential pattern and prognostic significance of CD4+, FOXP3+ and IL-17+ tumor infiltrating lymphocytes in ductal and lobular breast cancers. BMC Cancer. 2012; 12(1):1. [DOI:10.1186/1471-2407-12-134] [PMID] [PMCID]

[29] Whiteside TL. What are regulatory T cells (Treg) regulating in cancer and why? Seminars in cancer biology. London: Elsevier; 2012.
[30] Yamaguchi T, Wing JB, Sakaguchi S. Two modes of immune suppression by Foxp3+ regulatory $\mathrm{T}$ cells under inflammatory or non-inflammatory conditions. Seminars in immunology; 2011.

[31] Whiteside T. The tumor microenvironment and its role in promoting tumor growth. Oncogene. 2008; 27(45):5904-12. [DOI:10.1038/onc.2008.271] [PMID] [PMCID]

[32] Oberg H-H, Juricke M, Kabelitz D, Wesch D. Regulation of T cell activation by TLR ligands. European Journal of Cell Biology. 2011; 90(6):582-92. [DOI:10.1016/j.ejcb.2010.11.012] [PMID]

[33] Yoshie O, Matsushima K. CCR4 and its ligands: from bench to bedside. International Immunology. 2015; 27(1):11-20. [DOI:10.1093/intimm/dxu079] [PMID]

[34] Ondondo BO, Gallimore A, Jones EG, Godkin A. Home sweet home: The tumor microenvironment as a haven for regulatory T cells. Frontiers in Immunology. 2013; 4:197. [DOI:10.3389/fimmu.2013.00197] [PMID] [PMCID]

[35] Ladoire S, Martin F, Ghiringhelli F. Prognostic role of FOXP3+ regulatory $\mathrm{T}$ cells infiltrating human carcinomas: the paradox of colorectal cancer. Cancer Immunology, Immunotherapy. 2011; 60(7):909-18. [DOI:10.1007/s00262-0111046-y] [PMID]

[36] Rech AJ, Mick R, Kaplan DE, Chang K-M, Domchek SM, Vonderheide RH. Homeostasis of peripheral FoxP3+ CD4+ regulatory $\mathrm{T}$ cells in patients with early and late stage breast cancer. Cancer Immunology, Immunotherapy. 2010; 59(4):599-607. [DOI:10.1007/s00262-009-0780-x] [PMID]

[37] Salama P, Phillips M, Grieu F, Morris M, Zeps N, Joseph $\mathrm{D}$, et al. Tumor-infiltrating FOXP3+ T regulatory cells show strong prognostic significance in colorectal cancer. Journal of Clinical Oncology. 2009; 27(2):186-92. [DOI:10.1200/ JCO.2008.18.7229] [PMID]

[38] Frey DM, Droeser RA, Viehl CT, Zlobec I, Lugli A, Zingg U, et al. High frequency of tumor-infiltrating FOXP3+ regulatory $\mathrm{T}$ cells predicts improved survival in mismatch repairproficient colorectal cancer patients. International Journal of Cancer. 2010; 126(11):2635-43. [DOI:10.1002/ijc.24989]

[39] Duhen T, Duhen R, Lanzavecchia A, Sallusto F, Campbell DJ. Functionally distinct subsets of human FOXP3+ Treg cells that phenotypically mirror effector Th cells. Blood. 2012; 119(19):4430-40. [DOI:10.1182/blood-2011-11-392324] [PMID] [PMCID]

[40] Francisco LM, Salinas VH, Brown KE, Vanguri VK, Freeman GJ, Kuchroo VK, et al. PD-L1 regulates the development, maintenance, and function of induced regulatory T cells. The Journal of Experimental Medicine. 2009; 206(13):301529. [DOI:10.1084/jem.20090847] [PMID] [PMCID]

[41] Camisaschi C, Casati C, Rini F, Perego M, De Filippo A, Triebel F, et al. LAG-3 expression defines a subset of CD4+ $\mathrm{CD} 25$ highFoxp3+ regulatory $\mathrm{T}$ cells that are expanded at tumor sites. The Journal of Immunology. 2010; 184(11):654551. [DOI:10.4049/jimmunol.0903879] [PMID]

[42] Jie H, Gildener-Leapman N, Li J, Srivastava R, Gibson S, Whiteside $\mathrm{T}$, et al. Intratumoral regulatory $\mathrm{T}$ cells upregulate immunosuppressive molecules in head and neck cancer patients. British Journal of Cancer. 2013; 109(10):2629-35. [DOI:10.1038/bjc.2013.645] [PMID] [PMCID] 
[43] Colombo MP, Piconese S. Regulatory T-cell inhibition versus depletion: the right choice in cancer immunotherapy. Nature Reviews Cancer. 2007; 7(11):880-7. [DOI:10.1038/ nrc2250] [PMID]

[44] Chang LY, Lin YC, Mahalingam J, Huang CT, Chen TW, Kang CW, et al. Tumor-derived chemokine CCL5 enhances TGF- $\beta$-mediated killing of CD8+ T cells in colon cancer by t-regulatory cell. Cancer research. 2012; 72(5):1092-102. [DOI:10.1158/0008-5472.CAN-11-2493] [PMID]

[45] Betts G, Jones E, Junaid S, El-Shanawany T, Scurr M, Mizen $\mathrm{P}$, et al. Suppression of tumour-specific CD4+ T cells by regulatory $\mathrm{T}$ cells is associated with progression of human colorectal cancer. Gut. 2012; 61(8):1163-71. [DOI:10.1136/ gutjnl-2011-300970] [PMID] [PMCID]

[46] Byrne WL, Mills KH, Lederer JA, O'Sullivan GC. Targeting regulatory $\mathrm{T}$ cells in cancer. Cancer Research. 2011; 71(22):6915-20. [DOI:10.1158/0008-5472.CAN-11-1156] [PMID] [PMCID]

[47] Medina-Echeverz J, Fioravanti J, Zabala M, Ardaiz N, Prieto J, Berraondo P. Successful colon cancer eradication after chemoimmunotherapy is associated with profound phenotypic change of intratumoral myeloid cells. The Journal of Immunology. 2011; 186(2):807-15. [DOI:10.4049/jimmunol.1001483] [PMID]

[48] Bonertz A, Weitz J, Pietsch DHK, Rahbari NN, Schlude C, Ge Y, et al. Antigen-specific Tregs control T cell responses against a limited repertoire of tumor antigens in patients with colorectal carcinoma. The Journal of Clinical Investigation. 2009; 119(11):3311-21. [DOI:10.1172/JCI39608]

[49] Izhak L, Ambrosino E, Kato S, Parish ST, O’Konek JJ, Weber $\mathrm{H}$, et al. Delicate balance among three types of T cells in concurrent regulation of tumor immunity. Cancer Research. 2013; 73(5):1514-23. [DOI:10.1158/0008-5472.CAN-12-2567] [PMID] [PMCID]

[50] Balachandran VP, Cavnar MJ, Zeng S, Bamboat ZM, Ocuin $\mathrm{LM}$, Obaid $\mathrm{H}$, et al. Imatinib potentiates antitumor $\mathrm{T}$ cell responses in gastrointestinal stromal tumor through the inhibition of Ido. Nature Medicine. 2011; 17(9):1094-100. [DOI:10.1038/nm.2438] [PMID] [PMCID]

[51] Villanacci V, Not T, Nascimbeni R, Ferrara F, Tommasini A, Manenti S, et al. Gastrointestinal Foxp3 expression in normal, inflammatory and neoplastic conditions. Pathology-Journal of the RCPA. 2011; 43(5):465-71. [DOI:10.1097/ PAT.0b013e3283485e37]

[52] Michel S, Benner A, Tariverdian M, Wentzensen N, Hoefler P, Pommerencke T, et al. High density of FOXP3-positive $\mathrm{T}$ cells infiltrating colorectal cancers with microsatellite instability. British Journal of Cancer. 2008; 99(11):1867-73. [DOI:10.1038/sj.bjc.6604756] [PMID] [PMCID]

[53] Lee H, Park D, Kim W, Kim H, Lee H. High FOXP3+ regulatory T-cell density in the sentinel lymph node is associated with downstream non-sentinel lymph-node metastasis in gastric cancer. British Journal of Cancer. 2011; 105(3):413-9. [DOI:10.1038/bjc.2011.248] [PMID] [PMCID]

[54] Khazaie K, Bonertz A, Beckhove P. Current developments with peptide-based human tumor vaccines. Current Opinion in Oncology. 2009; 21(6):524-30. [DOI:10.1097/ CCO.0b013e328331a78e] [PMID]
[55] Mougiakakos D. Regulatory T Cells in Colorectal Cancer: From Biology to Prognostic Relevance. Cancers. 2011; 3(2):1708-31. [DOI:10.3390/cancers3021708] [PMID] [PMCID]

[56] Zeng H, Chi H. Metabolic control of regulatory T cell development and function. Trends in Immunology. 2015; 36(1):312. [DOI:10.1016/j.it.2014.08.003] [PMID] [PMCID]

[57] Terme M, Pernot S, Marcheteau E, Sandoval F, Benhamouda N, Colussi O, et al. VEGFA-VEGFR pathway blockade inhibits tumor-induced regulatory T-cell proliferation in colorectal cancer. Cancer Research. 2013; 73(2):539-49. [DOI:10.1158/0008-5472.CAN-12-2325] [PMID]

[58] Singer B, King L. D' Alessio FR. Regulatory T cells as immunotherapy. 2014; 5:46. 